\title{
Uma proposta pedagógica para ensinar probabilidade no Ensino Fundamental
}

\section{A proposal likely to teach teaching in Elementary Scholl}

\author{
${ }^{1}$ Rubia Juliana Gomes Fernandes \\ ${ }^{2}$ Guataçara dos Santos Junior
}

\section{RESUMO}

O objetivo deste trabalho é analisar as contribuições que a Sequência de Ensino (SE) pode trazer para o processo de ensino e aprendizagem de Probabilidade nos anos iniciais de escolarização. Com o intuito de atingir o objetivo apresentado, foi desenvolvida uma pesquisa numa turma de alunos do $4^{\circ}$ Ano do Ensino Fundamental de uma escola da Rede Municipal da cidade de Curitiba, estado do Paraná - Brasil. Para tal, foi trabalhada uma sequência de ensino direcionado aos conteúdos básicos de Probabilidade. A metodologia utilizada na pesquisa é aplicada, descritiva e os resultados foram analisados na perspectiva qualitativa. Ao analisar os resultados advindos do desempenho dos alunos durante a execução dessa proposta pedagógica, percebeu-se um avanço significativo quanto à aquisição dos conteúdos, conhecimentos e saberes envolvendo aos conhecimentos de Probabilidade.

Palavras-chave: Ensino. Aprendizagem. Probabilidade. Sequência de Ensino (SE).

\begin{abstract}
The objective of this work is to analyze the contributions that a sequence of instruction (SE) for the process of teaching and learning graphs and tables to the early years of schooling. In order to achieve the goal presented was developed in a research group of students of the 4th year of elementary school in a Municipal School of Curitiba, State of Parana - Brazil. The methodology used in this research is applied, descriptive, and the results were analyzed in qualitative terms. For data collection, we applied the students a diagnostic instrument with anterior and posterior to the application of Sequence Learning (IF) analysis. Analyzing the proceeds of student performance during the execution of this pedagogical proposal, it was noticed a significant advance on the acquisition of content knowledge and techniques involving the expertise of statistics, it is considered that the application of the SE.
\end{abstract}

Keywords: Statistics. Contextualization. Sequence of Instruction (SE).

\footnotetext{
1 Secretaria de Educação de Curitiba / PR.

2 Universidade Tecnológica Federal do Paraná / PR.
} 


\section{INTRODUÇÃO}

Atualmente o ensino da probabilidade está no foco de vários debates e discussões, em virtude da preocupação crescente com relação a está questão nos últimos anos. Acredita-se que o formato no qual estrutura-se a disciplina curricular de matemática nas instituições escolares pode configura-se como fator crucial, ao analisar e refletir o contexto educacional.

Nesse sentido, entende-se que essa conjectura pode ser resquícios do cenário educativo no tocante a educação matemática, na qual os pressupostos fundamentais sustentavam-se na mera mecanização de conceitos, procedimentos e a aplicação de técnicas operatórias. Esta concepção com relação ao processo de ensino e aprendizagem seria a justificativa do que imaginava ser função primordial das instituições escolares em perspectivas anteriores, o repasse/transmissão de informações aos alunos.

Com isso, as disciplinas e conteúdos curriculares estruturados em áreas do conhecimento estanques umas das outras e, por vezes, dentro de sim própria enquanto área do conhecimento. Para Bazzo (1998, p.34) os cidadãos "merecem aprender a ler, entender e compreender muito além dos conceitos trabalhados isoladamente em áreas específicas do conhecimento e sim, incorporando-os numa leitura de mundo, inferindo preceitos escolares”.

Entende-se que o ensino de matemática focado na probabilidade precisa ultrapassar o contexto escolar, haja vista a sua importância social. Para tanto, é essencial que a praticas pedagógicas extrapolem a simples sistematização de definição e reprodução da aplicação de estruturas algorítmicas operatória.

Reiterando as colocações apresentada, destaca-se a discussão de Skovsmose (2007, p. 208) ao pontuar que:

[...] a ideia da importância do conhecimento matemático teve ser compreendido como uma maneira de tornar o cidadão mais crítico. Mas isso não e fácil, principalmente quando a tradição da matemática escolar parece condicionar os estudantes apenas a executar comandos predefinidos por alguém superior a ele.

Compreende-se que associar conceitos matemáticos abordando a probabilidade a contextos de aplicabilidade é fundamental. Contudo, não é suficiente quando se almeja para oportunizar uma formação integral escolar de qualidade. Na qual o aluno tenha subsídios para associar e aplicar os saberes e conhecimentos educativos, em sua vida cotidiana.

Desta forma, acredita-se que a ação do professor é elemento primordial ao processo de ensino e aprendizagem, ao promover encaminhamentos pedagógicos que favorecem e instigam organização, apropriação e correlação dos conhecimentos probabilísticos pelos alunos, bem como provocar conflitos cognitivos que impulsiona, e propiciem o crescimento intelectual, podendo apoiar-se em jogos de regras para tal.

Portanto, o objetivo deste trabalho é analisar as contribuições que a Sequência de Ensino (SE) ${ }^{1}$ pode trazer para o processo de ensino e aprendizagem de Probabilidade nos anos iniciais de escolarização.

1 Destaca-se que a sequência de ensino utilizada nesta pesquisa está disponível em http://ppgect.pg.utfpr.edu.br/site/?page_id=344, consultando o ano 2014 e nome da autora deste artigo. 


\section{A PROBABILIDADE NO ENSINO FUNDAMENTAL}

As práticas pedagógicas pertinentes ao ensino da matemática nos anos iniciais estão passando por diversas transformações na tentativa de oportunizar aos estudantes uma educação de qualidade. Deste modo, essa pesquisa apresentará alguns aspectos compreendidos como importantes no processo de ensino e aprendizagem desta disciplina.

Com relação à educação estatística abarcando a probabilidade percebe-se que esta pretende oportunizar e contribuir para o desenvolvimento do pensamento estatístico e probabilístico, haja vista que estes conhecimentos são indispensáveis aos estudantes e indivíduos de modo geral.

As pressuposições com relação ao pensamento ou raciocínio probabilístico podem ser entendidas, como uma forma que os indivíduos têm para refletir matematicamente, pautando-se nos conhecimentos probabilísticos sobre as informações contidas em seu meio.

No que diz respeito ao pensamento probabilístico torna-se fundamental oportunizar aos alunos o embate com situações reais diversificadas como, por exemplo: jogos de regras, resolução de situações-problema que podem favorecer a elaboração de estratégias. A probabilidade:

É apresentada com a finalidade de promover a compreensão de grande parte dos acontecimentos do cotidiano que são de natureza aleatória, possibilitando a identificação de resultados possíveis desses acontecimentos. Destacam-se o acaso e a incerteza que se manifestam intuitivamente, portanto cabendo à escola propor situações em que as crianças possam realizar experimentos e fazer observações dos eventos (LOPES, 1998, p. 111).

Nesse aspecto, a probabili dde podem ser apresentadas utilizando o recurso da matematização que significa organizar, formular, sistematizar, criticar e desenvolver mecanismos próprios para compreender (SKOVSMOSE, 1990). Observa-se que, para que esse processo se efetive é indispensável que docentes e discentes encontrem-se no domínio da situação de aprendizagem.

O contexto de interação entre docentes, práticas pedagógicas e saberes deve ser organizado como uma tríade de entidades, interdependentes e co-pertencentes a um contexto de trabalho pedagógico que co-evolua e que, permanentemente, se transforme (FIORENTINI, 2000).

Essa dinâmica terá como objetivo, formar alunos críticos frente aos conteúdos matemáticos, bem como torná-los reflexivos e argumentativos com relação a decisões em âmbito social e, em especial, em circunstâncias nas quais os conhecimentos e saberes matemáticos são ferramentas indispensáveis para o entendimento e compreensão do seu cotidiano. Mediante essas circunstâncias "é preciso tornar os alunos, pessoas capazes de enfrentar situações e contextos variáveis, que exijam deles a aprendizagem de novos conhecimentos e habilidades” (POZO, 1998, p. 9).

Com relação à estatística na sociedade atual pode-se perceber que é cada vez maior o volume de informações inseridas na vida cotidiana dos indivíduos que os remetem a esse conhecimento. Nesta perspectiva "a estatística constitui uma importante ferramenta para a realização de projetos e investigações em numerosos domínios” (PONTE, 2005, p. 91), sendo utilizada no planejamento, na coleta e na análise de dados, bem como na realização de inferências para tomar decisões.

Tendo como referência uma perspectiva crítica do ensino da matemática percebe-se que a estatística e probabilidade:

[...] se mostra como conhecimento que contribui para o desenvolvimento de processos de pensamento, raciocínio e aquisição de atitude, cuja utilidade e alcance transcendem o âmbito do próprio conhecimento. Isso vem favorecer ao aluno a capacidade de resolver problemas, gerando nele hábitos de investigação, proporcionando-lhe confiança e desprendimento para analisar e enfrentar situações novas, bem como propiciando-lhe a formação de uma visão ampla da realidade (PINHEIRO, 2005, p. 17). 
Dessa forma, atuar nessa perspectiva de selecionar, analisar e refletir, tem sido um grande e constante desafio educativo. Tendo em vista esses apontamentos, observa-se a necessidade da sistematização dos mesmos durante as práticas pedagógicas, contribuindo para a formação de cidadãos autônomos, capazes de pensar e tomar decisões sobre os acontecimentos que os cercam.

A dinâmica docente deverá extrapolar as paredes da sala de aula, contextualizando o que foi construído no âmbito científico e tecnológico, permitindo "aos alunos compreenderem que tal conhecimento não foi algo construído linearmente e que resultou das necessidades que as pessoas tinham em dominar a natureza” (PINHEIRO, 2005, p. 79). Desta forma pode-se contribuir para tornar os alunos agentes ativos das suas próprias aprendizagens significando-as num contexto real.

Lopes (1998, p. 11-12) afirmar que o "ensino e probabilidade são conhecimentos fundamentais para analisar índices de custo de vida, para realizar sondagens, escolher amostras e outras situações do cotidiano.” A probabilidade é uma maneira de mensurar a incerteza e matematizá-la, favorecendo a aplicação destes conceitos em situações-problema reais dos indivíduos ou artificiais para a experimentação (LOPES, 1998).

Ao corroborar com o apresentado, Coutinho (2009), menciona que para sistematizar os conceitos e procedimentos com os alunos da educação básica é essencial lhes permitir vivenciar efetivamente os processos de experimentação científica, do ponto de vista do desenvolvimento do raciocínio probabilístico.

Nesta perspectiva, o fio condutor com relação à aprendizagem matemática, é tentar possibilitar a estruturação e o desenvolvimento do trabalho didático pedagógico da probabilidade no ambiente escolar, pois se entende que do mesmo modo que a matemática se desenvolveu a partir da necessidade dos indivíduos em resolver problemas de ordem prática, os conceitos probabilísticos seguiram a mesma lógica. Portanto, entende-se que a resolução de problemas, jogos de regras, os recursos tecnológicos entre outros podem auxiliar muito as práticas educativas.

\section{ENCAMINHAMENTOS METODOLÓGICOS}

Os sujeitos da pesquisa foram 35 alunos de uma turma do $4^{\circ}$ ano do Ensino Fundamental, de uma escola da Rede Municipal da cidade de Curitiba, estado do Paraná - Brasil. O conjunto de dados coletados para a pesquisa é composto por anotações realizadas pela pesquisadora, atividades realizadas pelos alunos e fotografias. Para facilitar a descrição e a análise dos dados e com o intuito de preservar o anonimato dos alunos, estes foram nomeados pela letra A seguida de um número.

Esta pesquisa se caracteriza por aplicada, descritiva e os resultados foram analisados na perspectiva qualitativa. Sendo necessárias três etapas para o seu desenvolvimento e aplicação (pré-teste, aplicação da SE e pósteste), distribuindo-se da seguinte forma:

\section{$1^{\circ}$ Momento: Aplicação do pré-teste a priori da SE}

Aplicou-se para os alunos um instrumento diagnóstico denominado de (pré-teste), que tinha como intuito central averiguar quais as habilidades, competências e conhecimentos relativos aos conteúdos de Probabilidade.

As questões elencadas são advindas das Avaliações da Secretaria da Municipal de Educação (SME) e Jornada de Resolução de Problemas de Matemática da Rede Municipal de Educação de Curitiba (JRPM) e questões adaptadas de um livro didático dos anos iniciais do Ensino Fundamental. Para esse momento utilizou-se uma aula de 50 minutos. Tais questões podem ser observadas, por meio das análises e discussões de resultados nos quadros 1,2 e 3. 


\section{$2^{\circ}$ Momento: Explorando em sala de aula a Sequência de Ensino (SE)}

A Sequência de Ensino (SE) teve como intuito abordar questões referentes aos conhecimentos e saberes de Probabilidade como o principio da combinação, espaços amostrais equiprováveis, por meio da contextualização utilizando os dados coletados com a própria turma. Para efetivação desse momento da pesquisa utilizaram-se 5 aulas cada uma com 50 minutos.

No decorrer da aplicação da SE foram analisada as atitudes e a postura dos alunos, as quais se reportam à predisposição, empenho, motivação, na busca por soluções valorizando a troca de experiências com seus pares como forma de aprendizagem e, assim, compreendendo a importância do trabalho coletivo.

\section{$3^{\circ}$ Momento: Aplicação do pós-teste a posteriori da SE}

Nesse momento, aplicou-se aos estudantes um instrumento diagnóstico denominado (pós-teste). Cabe destacar, que ele apresentava as mesmas questões do pré-teste, sendo necessária a utilização de uma aula de 50 minutos. Portanto, foi possível comparar os resultados obtidos pelos alunos no pós-teste e pré-teste, com a intenção de verificar os progressos alcançados, bem como pontuar as dificuldades que ainda necessitam serem superadas após o trabalho pedagógico com a (SE).

\section{APRESENTAÇÃO, ANÁLISE E DISCUSSÃO DOS RESULTADOS}

\section{1 Análise $-\mathbf{1}^{\mathrm{a}}$ Questão}

A primeira questão teve por objetivo verificar a habilidade dos alunos em sistematizar a ideia de probabilidade num determinado evento (espaço amostral equiprovável). Também objetivou-se identificar eventos reais em que é possível fazer uso de noções de probabilidade (espaço amostral equiprovável).

No quadro 1 a seguir, é possível observar a questão inicial que foi apresentada no pré-teste:

Quadro 1 - Questão do pré-teste

\begin{tabular}{|l|}
\hline \multicolumn{1}{|c|}{ QUESTÃO 1} \\
\hline 1- A ficha é azul de um lado e vermelha do outro. Se a ficha for lançada para o alto, qual é o lado \\
que terá mais chance de cair virado para cima? \\
a) o vermelho \\
b) o azul \\
c) as chances são as mesmas \\
d) nenhuma das duas cores
\end{tabular}

Fonte: SME Curitiba

\subsubsection{Análise da Questão 1 - a priori}

Na análise das respostas dadas pelos alunos com relação à questão proposta, percebeu-se que $40 \%$ dos pesquisados conseguiram determinar a resposta correta para o solicitado.

Com relação aos outros alunos da amostra, verificou-se que 23,3\% dos pesquisados acreditavam que a chance de obter a cor vermelha era superior a de obter a cor azul. Nesse sentido, ficaram evidentes as ideias equivocadas de $36,7 \%$ do restante dos alunos ao afirmarem que a chance de obter a cor azul era superiores a de obter a cor vermelha. Contudo, não foi constatada a presença de nenhuma resposta que correspondesse à ideia de, ao jogar a ficha para cima, não encontrar nenhuma das cores apresentadas (azul e vermelha). 
A esse respeito, vale destacar as colocações de Evangelista Sobrinho (2010) ao perceber que erros dessa natureza também foram cometidos por estudantes do $6^{\circ}$ ano, durante o processo interventivo aplicado por ele em sua pesquisa de mestrado.

Deste modo, constata-se ainda a dificuldade de mais da metade dos pesquisados com relação às ideias relativas às noções probabilísticas (equiprobabilidade), conforme apontam autores que corroboram com os indicativos encontrados nessa pesquisa. Assim, é possível refletir as colocações de Goulart (2010) reiterando o exposto por Coutinho (2001) ao recomendar maior importância aos conceitos fundamentais para a Educação Básica, como conhecimentos imprescindíveis para a construção do conceito de probabilidade, a ideia de experiências aleatórias e as noções de probabilidade.

\subsubsection{Análise da Questão 1 - a posteriori}

Baseando-se na análise dos resultados do pós-teste verificou-se que houve um aproveitamento favorável de $94,2 \%$ dos alunos investigados. Tal percentual significou uma acréscimo significativo de 54,2\% quanto comparado ao pré-teste no qual os alunos obtiveram somente $40 \%$ de acerto.

Coutinho (1994) observou em sua pesquisa, ao abordar essa ideia probabilística (chances), que de 30 alunos pesquisados apenas 9\% indicaram a resposta correta, mostrando compreender esse conceito de probabilidade, e 91\% não tiveram subsídios para responder coerentemente.

Nesse sentido, cabe destacar que, ao tratar da ideia de Probabilidade (chances), Stelmastchuki (2009), em sua pesquisa com alunos do $5^{\circ}$ ano (ciclo II) do Ensino Fundamental, dividiu a sua amostra em três unidades escolares denominadas como (escola A, escola B e escola C), atingindo o total de 88 alunos.

Na escola A, participaram da coleta de dados 34 alunos, e a autora obteve 5,88\% de aproveitamento nesse quesito. Já na escola B, dos 27 alunos pesquisados, nenhum deles conseguiu responder corretamente perfazendo $0 \%$ de aproveitamento, e, na escola C, dos 27 alunos que participaram, houve 62,96\% de aproveitamento com relação a esse conteúdo. Com isso, constata-se que dentre os 88 alunos distribuídos nas três escolas, o índice de aproveitamento foi somente de 21,59\%, chamando a atenção o fato de nenhum aluno da escola B ter conseguido responder corretamente.

Evangelista Sobrinho (2010) também notou grande dificuldade dos alunos do $6^{\circ}$ ano, com relação à ideia de Probabilidade (chances) em seu estudo, pontuando que eles não haviam compreendido e nem construído com clareza o raciocínio probabilístico, envolvendo as ideias de chances, os valores aleatórios e as possibilidades existentes. O autor indica que esse panorama tão somente ratifica suas hipóteses referentes à existência de uma lacuna conceitual no processo de ensino e aprendizagem em relação aos conhecimentos probabilísticos e raciocínio combinatório que os alunos apresentam, o que, segundo ele, é oriunda dos anos iniciais da escolarização do Ensino Fundamental.

Outro fator curioso é que mesmo com as orientações de estudiosos e pesquisadores, como Coutinho (2011), Lopes (1998; 2003), Oliveira (2005), entre outros, ainda se percebe que há poucos encaminhamentos pedagógicos direcionados a esse campo de estudo. Esse fato pode ser constatado facilmente ao analisar os dados das pesquisas recentes relativas a essa questão em específico, como nos estudos de Evangelista Sobrinho (2010), Stelmastchuki (2009) e a presente pesquisa do ano de 2013.

\section{2 Análise $-2^{\mathrm{a}}$ Questão}

A segunda questão teve por verificar a habilidade dos alunos referente à noção de combinação de elementos, num determinado evento. Bem como, averiguar se os alunos fazem uso das ideias de combinatória para solucionar uma situação-problema.

No quadro 2 a seguir, é possível observar a segunda questão apresentada no pré-teste: 


\section{Quadro 2 - Questão do pré-teste}

\begin{tabular}{|l|}
\hline \multicolumn{1}{|c|}{ QUESTÃO 2 } \\
\hline $\begin{array}{l}\text { 2- Com os algarismos 2, 4, 6 e 8, quantos números naturais formados por três algarismos diferentes } \\
\text { você poderá formar? Escreva todas as possibilidades. }\end{array}$ \\
\hline
\end{tabular}

Fonte: SME Curitiba.

\subsubsection{Análise da Questão 2 - a priori}

Por meio das respostas do instrumento diagnóstico, observou-se que somente dois alunos (A2, A15), ou seja, 5,7\% da amostra determinaram as combinações e, com isso, a resposta correta para a questão proposta.

Assim, os outros 33 pesquisados, que correspondem a 94,2\% dos estudantes que responderam erroneamente o solicitado, distribuem-se da seguinte forma: 17,1\% dos alunos realizaram as combinações esquecendo no máximo três combinações quaisquer, e, por conta desse fato, não conseguiram obter o número correto de combinações, contudo foi perceptível que compreenderam a ideia de combinar. Já 37,1\% dos alunos demonstraram não compreender os princípios combinatórios, ao apresentarem como resposta para as combinações os próprios algarismos 2,4,6 e 8.

Além disso, 28,5\% da amostra pesquisada demonstraram não compreender o que a questão solicitava, pois apresentaram como resposta as combinações dos próprios algarismos 2,4,6 e 8 repetidos três vezes, e 11,4\% realizaram combinações com dois algarismos, três e até quatro, mas nesse caso sem repetição de algarismos.

A esse respeito, Sobrinho (2010) também encontrou em seu estudo problemas semelhantes, afirmando que é possível observar que a linguagem probabilística é uma problemática para os estudantes, pois não tinham familiaridade com ela e, por vezes, não a compreendiam. Além disso, Evangelista Sobrinho (2010), ao analisar os dados de sua pesquisa em que havia questões que os alunos necessitam combinar elementos para resolver uma situação problema, percebeu a acentuada dificuldade na execução da atividade. Assim, destacou que os alunos nos anos iniciais dos alunos do Ensino Fundamental não tinham trabalhado com as ideias de combinatória (árvore de possibilidades) ou não haviam construído conhecimento necessário para aplicar essa estratégia às resoluções de problemas.

Daí a importância, conforme reflexões de Godino e Batanero (1994), da necessidade de se reverem as práticas educativas e os discursos pedagógicos, que objetivam nortear os processos de ensino e aprendizagem dos conceitos e conhecimentos probabilísticos na Educação Básica.

Portanto, é fundamental que os docentes tenham clareza das determinações advindas dos Parâmetros Curriculares Nacionais - PCN (Brasil, 1997, p.57) quanto à combinatória, bem como possuam ferramentas pedagógicas para sistematizar esse conteúdo em sala de aula, que tem como “objetivo levar o aluno a lidar com situações-problema que envolva combinações, arranjos, permutações e, especialmente, o princípio multiplicativo da contagem”.

\subsubsection{Análise da Questão 2 - a posteriori}

Com base nas respostas dadas pelos alunos em relação à questão proposta, verificou-se que os alunos obtiveram apenas 5,7\% de aproveitamento no pré-teste, deixando muito evidente que a amostra pesquisada apresenta grande dificuldade em relação aos conceitos da combinatória.

Dessa forma, surgiram problemas diversos, pois alguns alunos apresentaram como resposta para as combinações, os próprios algarismos 2,4,6 e 8. Outros não deram conta de realizar a interpretação da situação-problema ao apresentarem como resposta as combinações dos próprios algarismos 2,4,6 e 8 repetidos três vezes. Ainda houve os que realizaram combinações com dois algarismos, três e até quatro, mas nesse caso sem repetição de algarismos. 
Nessas resoluções, os alunos empregaram estratégias intuitivas de enumeração não sistemáticas ou parcialmente sistemáticas e não conseguiram determinar todos os agrupamentos. Foi possível encontrar a descrição desse mesmo erro nos estudos de Batanero (1996).

Desse modo, mesmo após a intervenção pedagógica, por meio da Sequência de Ensino, somente 74,2\% dos alunos obtiveram aproveitamento. Ao pensar no desempenho da turma coletivamente considera-se mediano esse indicativo; em contrapartida, ao se observar que existiu um acréscimo de 68,5\% de aproveitamento no pósteste, nesse quesito, entende-se um progresso expressivo.

Entretanto, distante ainda das pretensões e objetivos intelectuais, destacados pelos PCN (BRASIL, 1997) documento oficial que nortearam essa pesquisa, ao se referirem às competências escolares que se almejam para os alunos do Ensino Fundamental nos anos iniciais.

Ao abordar tal questão em sua pesquisa, Evangelista Sobrinho (2010) necessitou realizar intervenções constantes com os alunos do $6^{\circ}$ Ano do Ensino Fundamental, com o objetivo de direcionar e facilitar a compreensão dos procedimentos adotados para efetivação da tarefa proposta para os alunos. Destacou que eles não tinham recursos suficientes para resolver o problema, e até mesmo para interpretá-lo, porque houve mudança na quantidade de elementos a serem combinados.

Concluindo, isso sugere que nos anos iniciais de escolarização, os alunos não tiveram a oportunidade de trabalhar com esse conceito da combinatória ou não haviam construído os conhecimentos necessários para aplicar em contextos diferentes, ou seja, estavam utilizando os conceitos de forma mecânica e sem significação, não conseguindo abstrair para outras situações.

Baseando-se na análise desses testes (pós-testes e pré-testes) verificou-se que, embora Piaget (1972) tenha afirmado que adolescentes são capacitados para resolver situações-problema simples de combinatória, aplicando procedimentos também simples como a enumeração, os alunos em questão não demonstraram a habilidade de enumerar ou o fizeram de forma ineficaz. Averiguou-se também que havia alguns conceitos matemáticos fundamentais que não faziam parte do repertório intelectual dos alunos até o presente momento.

\section{3 Análise $-3^{\mathrm{a}}$ Questão}

A terceira questão teve por objetivo verificar a habilidade dos alunos com relação à ideia de Probabilidade (espaço amostral). Além de investigar se os alunos percebem, em eventos reais, a possibilidade da utilização de ideias de Probabilidade (espaço amostral) para solucionar uma situação-problema.

No quadro 3 a seguir, é possível observar a terceira questão aplicada no pré-teste.

\section{Quadro 3 - Questão do pré-teste}

QUESTÃO 3

3- Ao jogarmos um dado, qual a chance de tirarmos um número par?

a) uma chance em seis

b) duas chances em seis

c) três chances em seis

d) quatros chances em seis 


\subsubsection{Análise $-3^{\mathrm{a}}$ Questão a priori}

Baseando-se na análise das respostas dos alunos para a questão, percebeu-se que somente 17,2\% responderam corretamente ao solicitado, indicando que havia três chances em seis possibilidades para retirar um número par no lançamento de um dado com seis faces. Já 57,1\% da amostra estudada verificaram que havia duas chances em seis possibilidades. Acredita-se que a grande maioria dos alunos apresentou essa configuração como sendo a correta, por considerar somente duas situações (par e ímpar) sem classificar as fases do dado, conforme suas quantidades (2, 4, 6 como números pares e 1, 3, 5 como números ímpares). Outros 14,2\% dos alunos mencionaram que era possível obter uma chance em seis possibilidades, e 11,4\% afirmaram ser possível obter quatro chances no espaço amostral de seis possibilidades. Desse modo, percebe-se que praticamente metade da amostra estabeleceu um raciocínio equivocado para a questão.

Em sua pesquisa, Stelmastchuk (2009), com estudantes do ciclo II do Ensino fundamental (escola denominada como A por ela), debruça-se numa questão parecida como a apresentada, propondo o lançamento de uma moeda. Pôde perceber que, dos 34 alunos pesquisados, somente 2, ou seja, 5,88\% dos estudantes apresentaram a resposta correta, categorizada da seguinte forma: "Respostas que explicitam que as chances de cada jogador são iguais, justificadas corretamente”. Já a grande maioria, correspondendo a 20 alunos, ou seja, 58,82\%, se enquadra na seguinte categorização: "Respostas que apontam que as chances de cada jogador são iguais, porém, não apresentam justificativas, ou ainda, apresentam justificativa incompleta”.

Ainda nesse sentido, Lopes (2003) aponta como resultado de sua pesquisa a importância de se aprofundarem as discussões em relação ao desenvolvimento do pensamento estatístico e probabilístico. Que implicações eles têm no desenvolvimento da criança? Como trabalhá-los na sala de aula? Evidenciou também como necessário pensar nos conceitos que devem ser abordados, a fim de garantir a possibilidade de desenvolvimento de uma visão estatística e probabilística significativa por parte dos alunos. Além disso, percebeu a necessidade de se repensar o ensino de Estatística e Probabilidade na formação dos professores.

\subsubsection{Análise da Questão 3 - a posteriori}

Baseando-se na análise das respostas dos alunos no pós-teste, verificou-se que o seu aproveitamento e desempenho com relação ao conteúdo de probabilidade (chances) sofreu um crescimento significativo de 71,3\% ao comparar com o pré-teste. Observou-se, então, que $88,5 \%$ dos alunos pesquisados responderam corretamente a questão indicando que teriam três possibilidades (chances) num espaço amostral de seis possibilidades (chances), ou seja, 50\% de probabilidade de retirar tanto um número par quanto um ímpar.

Os outros $11,5 \%$ restantes indicaram como corretas duas possibilidades (chances) no espaço amostral de seis possibilidades (chances). Acredita-se que os alunos incorreram em tal erro por analisar somente duas situações referentes aos números apresentados nas faces do dado como par e ímpar, sem refletir que o dado tem seis faces divididas em números que variam de 1 a 6 , sendo (2,4, 6 como números pares e 1, 3, 5 como números impares). Portanto, conclui-se que praticamente quase toda a amostra ressignificou sua compreensão sobre o raciocínio probabilístico aplicado na resolução da atividade proposta.

Os PCN (BRASIL, 1998) indicam que o trabalho pedagógico precisa viabilizar o entendimento por parte do aluno com relação ao significado de espaço amostral e suas construções pela contagem dos casos possíveis. Cabe mencionar as colocações de Evangelista Sobrinho (2010) e Batanero (1996), quando destacam que as dificuldades acentuadas dos alunos com relação à Probabilidade podem ser decorrentes do desenvolvimento probabilístico inadequado.

Portanto, considerando o exposto até o momento, por meio da sistematização da Sequência de Ensino (SE), é possível considerar que os alunos evoluíram significativamente no que se refere à apropriação de conhecimentos e competências probabilísticas, assim apresenta-se quadro 4 a seguir: 


\section{Quadro 4 - Síntese da análise e discussão de dados}

\begin{tabular}{|c|l|l|l|c|c|}
\hline Questão & \multicolumn{1}{|c|}{ Conteúdo } & \multicolumn{1}{c|}{ Objetivo } & $\begin{array}{c}\text { Conhecimentos e competências } \\
\text { de estatística e probabilidade }\end{array}$ & $\begin{array}{c}\text { Pré-teste } \\
\mathbf{( \%} \text { de } \\
\text { acertos) }\end{array}$ & $\begin{array}{c}\text { Pós-teste } \\
\text { (\% de } \\
\text { acertos) }\end{array}$ \\
\hline 1 & $\begin{array}{l}\text { Espaço amostral } \\
\text { equiprovável }\end{array}$ & $\begin{array}{l}\text { Verificar a habilidade do aluno } \\
\text { em determinar os espaços } \\
\text { amostrais equiprováveis }\end{array}$ & Raciocínio probabilístico & $40 \%$ & $94,2 \%$ \\
\hline 2 & Combinatória & $\begin{array}{l}\text { Verificar a habilidade do aluno } \\
\text { para realizar a combinação de } \\
\text { elementos num determinado } \\
\text { evento. }\end{array}$ & Raciocínio combinatório & $5,7 \%$ & $71,4 \%$ \\
\hline 3 & Probabilidade & $\begin{array}{l}\text { Verificar a habilidade do } \\
\text { aluno em utilizar as chances } \\
\text { para solucionar uma situação- } \\
\text { problema em eventos reais. }\end{array}$ & Raciocínio probabilístico & $17,2 \%$ & $88,5 \%$ \\
\hline
\end{tabular}

Fonte: Autores

\section{CONSIDERAÇÕES FINAIS}

Apoiando-se na análise realizada nas respostas dadas pelos alunos no pré-teste, foi possível considerar insatisfatório o desempenho escolar prévio deles com relação aos conceitos de Probabilidade e Combinatória. Uma vez que tais conteúdos são considerados básicos e, que são indicados para o trabalho pedagógico desde os anos iniciais do Ensino Fundamental nas instituições escolares, por meio dos PCN.

Por meio do pré-teste, percebeu-se que os alunos apresentavam dificuldades acentuadas em questões simples como: noções envolvendo a probabilidade e combinatória.

A partir da aplicação e desenvolvimento da SE, constatou-se um avanço significativo com relação ao desempenho e aproveitamento dos alunos, principalmente quanto ao entendimento das noções básicas de probabilidade e combinatória. Bem como, a formação básica escolar com vistas aos saberes de Probabilidade nos alunos, para que eles tenham subsídios acadêmicos para futuramente atingir o nível de letramento probabilístico que a contemporaneidade exige dos sujeitos.

Verificou-se em cada uma das questões propostas e já discutidas, constatou-se que houve um avanço significativo no desempenho e aproveitamento dos alunos do $4^{\circ}$ ano do Ensino Fundamental em relação aos conteúdos de Probabilidade. Fator que se reflete no desenvolvimento das competências estatísticas e probabilísticas dos alunos.

Portanto, compreende-se que o objetivo deste trabalho foi atingido, uma vez que constatou-se as contribuições de uma Sequência de Ensino (SE) pode trazer para o processo de ensino e aprendizagem da Estatística e Probabilidade nos anos iniciais de escolarização. 


\section{REFERÊNCIAS}

BRASIL. Programa Nacional do Livro Didático do Ensino Fundamental. PNLEM - 2009. Brasília: MEC/ SEB, 2008.

BRASIL. Secretaria de Educação Fundamental. Parâmetros Curriculares Nacionais: ensino fundamental introdução. Rio de Janeiro: DP\&A, 1997a.

BRASIL. Parâmetros Curriculares Nacionais: Matemática. Brasília: MEC/SEF, 1997b.

BAZZO, W. A. Ciência, Tecnologia e Sociedade e o contexto da educação tecnológica. Florianópolis: EDUFSC, 1998.

COUTINHO, C. Q. S. Conceitos probabilísticos: quais contextos a história nos aponta? Revemat - Revista Eletrônica de Educação Matemática, v. 2, 2006.

COUTINHO, C. Q. S. Leitura e escrita em educação estatística. In: NACARATO, A. M. (Orgs.). Educação matemática, leitura e escrita: armadilhas, utopias e realidade. 1. ed. Campinas (SP): Mercado das Letras, 2009, v.1, p.61-78.

Introduction aux situations aléatoires dês collège: de la modélisations à la simulation d'expériences de Bernoulli dans l'environnement informatique cabrigéomètrell, 2001. Thèse (Doctorat) - Université Joseph Fourier, Grenoble (França), 2001.

EVANGELISTA SOBRINHO, F. O raciocínio combinatório e probabilístico de alunos do $\mathbf{6}^{\mathbf{0}}$ ano do ensino fundamental, 136 f. Dissertação (Mestrado em Educação) - Universidade Cruzeiro do Sul. São Paulo (SP), 2010.

GODINO, J. D.; BATANERO, C. Significado institucional y personal de los objetos matemáticos. Em: RECHERCHES em Didactique des athématiques, 1994, p.325-355.

PIAGET, J. Fazer e compreender. São Paulo: Melhoramentos, 1972.

PINHEIRO, M. A. N. Educação crítico(?)-reflexiva para o ensino médio científico-tecnológico: a contribuição do enfoque CTS para o ensino-aprendizagem do conhecimento matemático. Tese (Doutorado em Educação Científica e Tecnológica) - Universidade Federal de Santa Catarina. Florianópolis (SC), 2005.

Formar cidadãos crítico-reflexivos: a contribuição da matemática. Semina - Ciências Sociais e Humanas, v.28, p.81-91, 2007.

POZO, J. I. (Org.). A solução de problemas: aprender a resolver, resolver para aprender. Porto Alegre: Artmed, 2000.

A solução de problemas: aprender a resolver, resolver a para aprender. Porto Alegre: Artes Médicas, 1998.

OLIVEIRA, E. F. T. Análise a respeito de amostras aleatórias simples: uma aplicação na área de Ciência da Informação. DataGramaZero: Revista de Ciência da Informação, v.6, n.3, p.1-11, 2005.

SKOVSMOSE, O. Educação matemática crítica. São Paulo: Papirus, 1990.

Desafios da Reflexão em educação matemática crítica. Campinas: Papirus, 2008.

STElMASTCHUK, H. C. A. Probabilidade: significados atribuídos por alunos do Ciclo II do ensino fundamental. 2009. 111 f. Dissertação (Mestrado em Educação) - Setor de Educação, Universidade Federal do Paraná. Curitiba, 2009. 